\title{
Siglo XIX: La literatura peruana en proceso y la necesidad de replantearse la situación de los otros en la escena nacional
}

\section{Nineteenth century: Process of the Peruvian literature and the need to reconsider the situation of the others in the national scene}

Eduardo Huárag Álvarez*

Pontificia Universidad Católica del Perú

\section{Resumen}

El presente artículo espera contribuir a una necesaria revisión de las tendencias literarias que tuvieron mayor relevancia en el escenario cultural del Perú del siglo XIX. Se asume la perspectiva de que el costumbrismo representa la reafirmación del nosotros (nuestras costumbres, nuestra realidad social y cultural) frente a los otros (los españoles). Pero luego, en las siguientes décadas, durante el romanticismo, se aprecia que los criollos e intelectuales (el nosotros) no intenta un acercamiento a los otros (entendiendo como tal la población andina, la realidad rural del país). Solo después de la guerra con Chile, en términos generales, y con la participación singular de González Prada, los otros vuelven a ser motivo de reflexión y personajes de la actividad literaria. Para el estudio del proceso literario se han tenido en cuenta los textos

\footnotetext{
* Profesor ordinario-asociado de la especialidad de Lingüística y Literatura en dicha Universidad.

Contacto: ehuarag@pucp.pe
} 
de Palma y su testimonio personal, así como los escritos de Mercedes Cabello acerca de las tendencias literarias en su época. No se deja de lado la función del Estado frente a los intelectuales, especialmente a mediados del siglo XIX.

Palabras clave: movimientos literarios, Realismo, Romanticismo, novelas, Economía

\section{Abstract}

The purpose of this article is to contribute to a better understanding of the most important literary trends in the Peruvian cultural scenery of the nineteenth century. Costumbrismo is assumed as the reaffirmation of our national identity (our customs, our social and cultural reality) against the others (the Spaniards). However, in the following decades, during romanticism, Peruvian creoles and intellectuals did not attempt an approach to the others (that is, to the Andean population and the rural reality of the country). Only after the war against Chile and with the exceptional participation of Gonzalez Prada, the others became a matter of reflection and Andean peasants began to appear as characters of literary pieces. Palma works and his personal testimony were taken into account to study the literary process, as well as the writings of Mercedes Cabello about the literary trends of her time. The role of the government towards intellectual life, especially during the mid-nineteenth century has also been considered.

Key words: literary trends, Realism, Romanticism, novels, Economy 


\section{Una literatura en proceso y el nosotros en la República naciente}

La necesidad de caracterizar a la literatura peruana luego de la fundación de la República nos obliga a hacer algunas precisiones. Es evidente que la fecha de la independencia no significó un corte decisivo en el quehacer de los escritores. No cambiaron de la noche a la mañana los arquetipos o el canon literario que hasta entonces se utilizaba. La independencia permitió que los criollos asumieran el control del poder y que las actividades literarias siguieran desarrollándose desde la perspectiva de los intelectuales eruditos, en muchos casos vinculados a la tradición española. Se podría decir, inclusive, que los escritores, cronistas y periodistas solo se renovaron en tanto se interesaron en destacar lo propio, lo característico de cada país o región, tratando de configurar la identidad nacional, aquel nosotros americanista o regionalista que enaltecía lo suyo en contraposición a lo español. Fue así que se desarrolló el costumbrismo como tendencia literaria.

Una aproximación a la literatura en proceso necesariamente nos lleva a revisar el planteamiento de José Carlos Mariátegui. Es sabido que en sus 7 ensayos de la realidad peruana, Mariátegui (1952: 253) planteó que: “[...] el proceso normal de la literatura de un pueblo distingue en él tres periodos: un periodo colonial, un periodo cosmopolita, un periodo nacional. Durante el primer periodo un pueblo, literariamente, no es sino una colonia, una dependencia del otro. Durante el segundo periodo, asimila simultáneamente elementos de diversas culturas extranjeras. En el tercer periodo, alcanza una expresión bien modulada su propia personalidad y su propio sentimiento".

Luego, como para delimitar lo que considera colonial y cosmopolita, agrega que: "El ciclo colonial se presenta en la li- 
teratura peruana muy preciso y muy claro. Nuestra literatura no solo es colonial en ese ciclo por su dependencia y su vasallaje a España, lo es sobre todo, por su subordinación a los residuos espirituales y materiales de la Colonia" (1952: 253).

Como ejemplo de esa dependencia menciona a Felipe Pardo y Aliaga, a quien juzga tanto por la calidad de su obra como por su perspectiva o posición ideológica ante la naciente república. Señala que: “Toda la inspiración de su sátira -asaz mediocre por lo demás- procede de su mal humor de corregidor o de "encomendero" a quien una revolución ha igualado, en la teoría si no en el hecho, con los mestizos y los indígenas" (1952: 253-254).

Según Mariátegui, ese ciclo de colonización mental se prolonga "[...] hasta la generación "colónida" que, iconoclasta ante el pasado y sus valores, acata, como su maestro, a González Prada y saluda, como su precursor a Eguren, esto es a los dos literatos más liberados de españolismo" (1952: 254).

Aunque es verdad que los intelectuales de la república naciente siguieron ligados a la tradición española en sus tendencias y canon estético, lo que parece erróneo es que se considere que tal influencia se mantuvo hasta González Prada y, peor aún, hasta el movimiento colónida (es decir, el siglo XX). Es verdad que en el Perú las relaciones sociales y gran parte de la estructura económica habían cambiado poco desde la declaración de la independencia. De hecho, la situación del

120 indígena siguió siendo igual que en los tiempos de la colonia, sin derecho a participar en la vida democrática. Las costumbres y hábitos de los limeños, por ejemplo, siguieron siendo los mismos, como advierte Ricardo Palma en la tradición titulada El baile de la Victoria. Es cierto que González Prada representa el cuestionamiento al orden establecido, es el ideólogo que analiza la situación del país y pone en evidencia los errores del poder y la representatividad democrática. 
Sin embargo, desde antes se reconocía la influencia de los escritores franceses.

A modo de referencia mencionaremos que, según consigna Velásquez (2005: 11), entre 1839 y 1843 se publicaron 49 textos narrativos: "La mayoría de estos textos tenía entre 3 y 8 entregas, pero hubo varios que superaron las 15 entregas. El gran éxito de este primer periodo fue "Los misterios de París", de Eugéne Sue que se reprodujo en El Comercio entre agosto de 1843 y abril de 1844 superando las 160 entregas".

Poco antes de la aparición de la narrativa de folletín, el costumbrismo había mostrado sus mejores relatos. Obsérvese que Un viaje y Paseo de Amancaes, de Pardo y Aliaga, se publican en 1840; y Los carnavales y Las calles de Lima de Manuel A. Segura se publican en La Bolsa en 1841. Agréguese que el mismo autor publica Gonzalo Pizarro en 1844.

La publicación de otro tipo de narrativa, como las novelas de folletín, no significó que automáticamente el gusto y el paradigma estético cambiaran radicalmente. El costumbrismo, luego de la independencia, había permitido la reafirmación del nosotros (los americanos, los peruanos) frente a los colonialistas españoles. Confrontación que no fue tan radical en tanto que los costumbristas y sus epígonos continuaron, en el estilo, con las pautas establecidas por los españoles. Es cierto también que no fue copia burda del costumbrismo español. Los costumbristas peruanos incorporaron el humor criollo, la sátira y la caricatura. Como anota Ramos (1989: 19): "Escribir, a partir de 1820, respondía a la necesidad de superar la catástrofe, el vacío de discurso, la anulación de estructuras, que las guerras habían causado. Escribir, en ese mundo, era dar forma al sueño modernizador, era civilizar: ordenar el sinsentido de la "barbarie" americana".

En el Perú, escribir no significaba superar ninguna barbarie porque Lima, la capital del virreinato, tenía una larga tradi- 
ción cultural. Tampoco la reafirmación del nosotros significaría una distancia radical frente a lo español, pues el estilo se mantuvo endeudado a esa tradición. Tampoco dejemos de lado que junto a la literatura oficial, la de los intelectuales e ilustrados, la cultura oral también cultivaba su modo de narrar, aquello que respondía a su idiosincrasia, que era distinta del modo de entender la realidad de los españoles. En esa yuxtaposición de estilos y paradigmas, por ejemplo, no deja de llamar la atención que Luis Benjamín Cisneros escribiera, en 1886, la elegía A la muerte del rey Don Alfonso XII.

Nótese también que los manifiestos literarios relacionados con el sentimiento romántico se publican tardíamente en el Perú, cuando el movimiento en Europa (1820-1840 aproximadamente) había terminado. Uno de los primeros relatos románticos, Amor de niño, de Luis Benjamín Cisneros, se publica en 1864; Julia o escena de la vida en Lima, en 1861. A su vez, Ricardo Palma, otro de los que se inicia en el romanticismo, escribió su obra de teatro, El hijo del sol, en 1849, y Rodil, en 1851. Su libro Poesías recién aparece en 1865.

A diferencia de otros países, en el Perú, durante el romanticismo, los criollos, habitantes de la capital, descendientes de oligarcas, con acceso al poder central no se plantearon el dilema del nosotros frente a los otros, los ciudadanos de los Andes, los marginales. Salvo excepciones, esto se producirá luego de la guerra con Chile y la aparición de González Prada. En líneas generales, lo que refleja este distanciamiento

122 frente a los otros es la polarización de clases sociales. Los intelectuales, en su mayoría, eran conservadores y en el caso de Luis Benjamín Cisneros, era parte de una aristocracia que se benefició con la comercialización del guano de las islas.

No es cierto que la literatura peruana tuvo una dependencia colonial hacia España hasta González Prada (1895, aproximadamente). Con el romanticismo, y de modo más notorio con el realismo, la literatura peruana mantuvo como refe- 
rente a escritores franceses. No queremos decir tampoco que la literatura peruana rompiera todo vínculo con la literatura española. Lo que se formula es que los intelectuales se interesaron por la literatura de otros países europeos (lo que Mariátegui calificaría como cosmopolitismo), especialmente Francia. Cornejo Polar (1980, t. 8: 33) afirma que: "[...] nuestros poetas románticos repitieron temas y formas propios de los nativos franceses, españoles y -con menos asiduidad-alemanes".

Riva Agüero también había advertido la influencia francesa, aunque en su criterio los poetas y escritores no asimilaron la literatura francesa y siguieron tomando como referente a la literatura española. Dice Riva Agüero (1962, p. 136): "El periodo romántico de la literatura peruana principió, pues, en 1850 (o, como quiere Palma, en 1848). A partir de esa fecha se nota una nueva tendencia: la imitación directa de la poesía francesa. Sin embargo, siguió predominando la imitación española; y nuestro grupo de románticos, aunque leyera y estudiara asiduamente a Lamartine y Hugo, se inspiraba de preferencia en el romanticismo español".

Años después, en su Historia de la literatura hispanoamericana, José Miguel Oviedo precisa que el romanticismo se gestó en Alemania con el movimiento Sturm und Drang y que luego se propagó a toda Europa:

De Alemania e Inglaterra, la chispa romántica se propagó rápidamente a España y Francia, donde se convertirá en un verdadero programa literario con sus propagandistas y líderes, y de allí emigrará al resto de Europa, llegando tan lejos como a Rusia, con Pushkin y otros grandes poetas. Para Hispanoamérica, su paso y establecimiento en España es decisivo, porque el romanticismo hispano, junto con el francés, serán las dos fuentes más poderosas de influjos y modelos, aunque el segundo sea más visible en los momentos inaugurales del romanticismo americano (2005, t. 3: 14). 
Por tanto, cuando González Prada remece el escenario con su ideología y planteamientos radicales, ya había una apertura hacia la literatura europea en general, y más precisamente, francesa. Es importante saber que en el proceso de formación literaria de un país se producen trasvases, vasos comunicantes que provienen de diferentes tradiciones culturales. El Perú no es ajeno a ello. No olvidemos tampoco que los movimientos artísticos están muy ligados al acontecer social e histórico y que las ideas libertarias o el sentimiento de la nueva patria coincidían con la prédica de la libertad en la expresión literaria. Al respecto, Isabelle Tauzin sostiene:

Palma y los escritores de su generación recibieron la influencia del romanticismo europeo. El pensamiento romántico como rechazo del absolutismo y exaltación del liberalismo coincidía con la orientación política de las repúblicas americanas. El poeta se daba un cometido en la nueva sociedad en formación: había de ser el guía espiritual del pueblo; aspiraba a encaminarlo hacia la libertad y el progreso, lo que implicaba un compromiso con la vida política (1999: 18).

Es bueno aclarar que desde la perspectiva del planteamiento ideológico, los románticos tuvieron alguna aproximación a los gobiernos de turno. Aceptaron el orden establecido, salvo algunas diferencias por excesivo personalismo.

\section{El romanticismo y el escenario social latinoamericano}

Desde mediados del siglo XIX y en las décadas siguientes, dos son las tendencias predominantes: el romanticismo y el realismo. En ambos casos, las figuras paradigmáticas provienen de Francia. París fue el centro de donde se irradió el canon cultural y la innovación. El fenómeno se produce no solo en la literatura. También son figuras importantes pintores como Renoir, Degás, Toulouse Lautrec, Gauguin, Van 
Gogh, entre otros. En las primeras décadas del siglo XX, París continuó siendo capital de la innovación artística y allí se gestaron movimientos artísticos como el surrealismo, el dadaísmo, el vanguardismo y el cubismo. París fue la mítica ciudad que irradiaba creatividad, rebeldía e innovación.

En su momento, Víctor Hugo representó la innovación artística, la rebeldía frente a un clasicismo que se había aferrado a una retórica que suponían invariable. Pero la sociedad cambiaba y la literatura neoclásica no reflejaba tales cambios. Los neoclásicos eran intelectuales muy ilustrados y sus lectores tenían cierta formación académica. Sin embargo, la sociedad y los tiempos reclamaban temas e intriga más cercanos a la expresión cultural y popular, y eso es lo que plantearon los románticos. Los escritores románticos consideraban que la poética estaba más allá de las normas de poetización. Reafirmaron la individualidad y la libertad de las emociones y sentimientos. La poesía era más que el simple cumplimiento de una determinada métrica o rima. La poesía debía reflejar el estado emocional del artista y su libertad para crear. La palabra se debía someter a la explosión emocional. La novela, a su vez, adquirió un perfil especial. La novela, como el desarrollo de una intriga, iba de la mano con el desarrollo de las ciudades. Thibaudet considera que la aparición de la novela como género fue decisiva. Para él, el romanticismo: “[...] coincidió con el predominio extraordinario de un género que a veces ha parecido que debía absorber a los otros. El romanticismo es la revolución literaria menos por el lirismo y por el teatro que por la novela. No hay gran escritor, gran poeta romántico que no se haya creído obligado a sacrificar a la nueva divinidad, que no haya querido obtener por medio de ella los grandes éxitos del público" (1957: 114).

No es casual que, acompasado con la difusión de la prensa y la necesidad de fidelizar a los lectores para hacer que la industria de este medio alcance mayor desarrollo, apare- 
cieran las novelas de folletín. El público ávido podía seguir por entregas semanales la trama de una novela en la que un personaje o una familia sufrían los efectos de la crisis económica. Era frecuente que los personajes encontraran serios obstáculos para conseguir el amor de la amada y en no pocos casos el desenlace era trágico.

La irrupción del folletín y otros manifiestos culturales son signos de la época, de una literatura más cercana al consumo popular. Se percibe, cada vez más, que la obra literaria es un producto destinado a un público masivo. El lector es un consumidor anónimo que está pendiente de las obras que le ofrece el mercado cultural.

Pese a que el romanticismo simboliza la libertad en el acto creativo y en el desenvolvimiento del artista en la sociedad, sería erróneo creer que el romanticismo fue determinante para la gesta de la independencia o que debido a ese impulso idealista se produjo la independencia. Si se observan las fechas del romanticismo en Europa y el romanticismo en Hispanoamérica, se apreciará que el movimiento artístico-literario llega cuando los países ya han conseguido su independencia de la colonización española. Los hechos sociales y políticos tan significativos no se producen por un impulso emocional. La independencia de América se produjo por razones económico-sociales y las contradicciones insostenibles de una clase peninsular que deseaba seguir en el control del poder y una clase criolla que aspiraba a una presencia y control del gobierno de las regiones que empezaban a tener perfil propio.

Otro hecho importante es que, luego de la independencia, las nacientes repúblicas se encuentran en estado de crisis política y económica. En el Perú prevalece la inestabilidad y la devastación. Agréguese a ello el hecho de que la independencia no significó, como dijimos, un cambio importante para las mayorías, como los indios y mestizos. El régimen de pro- 
piedad, los modos de producción y las relaciones entre los grupos sociales siguieron manteniendo un orden en el que el control del poder estaba en manos del terrateniente. La sociedad no se había modernizado. Casi no existía actividad cultural. Oviedo (1965: 35) señala que: “[...] la década del 30 [se refiere a 1830] es, en el Perú, una época de transición, con escasa actividad, en que el neoclasicismo da algunos aletazos aislados y el romanticismo que ya agita Europa y el Río de la Plata permanece todavía inédito entre nosotros".

Es importante reiterar que las costumbres sociales no cambiaron con la independencia. Porras Barrenechea dice: "Pasado el turbión revolucionario, la ciudad recobró su fisonomía y sus costumbres coloniales (...) No habían desaparecido con la República las rígidas distinciones de casta, las "tapadas" seguían vistiendo su típico traje, aunque aprendieran a conspirar, y como los cuartelazos y la algarabía política no dejaba tiempo para innovaciones, la ciudad se conservaba inalterable" (1997: 32).

En esas primeras décadas de la República, la casta criolla seguía culturalmente afiliada a la tradición española. No sucedió lo mismo con los criollos de Río de La Plata que, por diversos motivos, mantuvieron una relación más intensa con Europa, especialmente con Francia. Esteban Echeverría viajó a París en 1826 y regresó a Buenos Aires cuatro años después. Publicó algunos poemas románticos en los periódicos locales y en 1837, La cautiva.

\section{La prosperidad económica y el mecenazgo del Estado}

La literatura no está desvinculada de los acontecimientos histórico-sociales. El siglo XIX y el Perú no son una excepción. A mediados del siglo XIX, la coyuntura favorece 
al Perú debido a la importancia del guano de las islas, un fertilizante muy apreciado en el mercado internacional. Se presenta, entonces, una época de bonanza que coincide con la consolidación del romanticismo. La burguesía agrícola se convirtió en consignataria y gracias a ello acumulan grandes fortunas. En 1869, el Estado relegó a los consignatarios y prefirió negociar directamente el fertilizante y emprender grandes obras para el país.

En ese periodo de estabilidad política y prosperidad económica el Estado asume una especie de mecenazgo a los intelectuales del país. Ricardo Palma, en La bohemia de mi tiempo señala que: "De 1848 a 1860 se desarrolló en el Perú, la filoxera literaria, o sea pasión febril por la literatura". En esos años, destacados jóvenes irrumpen en la vida artística: Arnaldo Márquez, Nicolás Corpancho, Adolfo García, Numa Pompilio Llona, Clemente Althaus, Luis Cisneros, Carlos Augusto Salaverry, Francisco Lazo, Pedro Paz Soldán y Unanue, entre otros.

La generación de jóvenes intelectuales con afanes artísticos sentía rechazo por la tendencia neoclásica, a la vez que una identificación plena con el romanticismo. Según Palma, a tal extremo llegaba la identificación y admiración por Víctor Hugo y Byron, que: "Márquez se sabía de coro a Lamartine; Corpancho no equivocaba letra de Zorrilla; para Adolfo García, más allá de Arolas no había poeta; Llona se entusiasmaba con Leopardi; Fernández, hasta en sueños recitaba las 128 doloras de Campoamor [...]” (1968: 1293).

Otro acontecimiento importante que vincula a la intelectualidad con el Estado benefactor es el hecho de que algunos funcionarios o ministros, como Miguel del Carpio, brindaron ayuda para promover la creación literaria, aunque los logros fueran limitados y, en no pocos casos, mediocres. Se buscó el aplauso del público estrenando obras de teatro que, como señala el mismo Palma, eran aceptables versificaciones 
que carecían de los fundamentos básicos de lo que supone una obra dramática y una concepción escénica. Los iniciados dramaturgos entendían de narrativa, pero no dominaban los recursos del arte escénico.

Cuando Miguel del Carpio asume la función de ministro de Estado, dice Palma que: "[...] los bohemios estábamos de plácemes; podíamos aspirar a todo y alcanzarlo todo" (1968: 1299). Lo cierto es que el Estado, en ese periodo, cumplió un rol de promotor o benefactor de los intelectuales: "A dos o tres de nosotros nos obsequió don Miguel del Carpio, y sin que lo solicitáramos, que en eso está el realce de su acción, unas canonjías de merced, que no otra cosa eran los títulos o nombramientos de oficiales del Cuerpo político de la Armada" (1968: 1299).

Si algo consolidó el romanticismo en el mundo literario es la reafirmación de la individualidad del creador y su libertad para crear. Libertad y curiosidad que se reflejaría en los intentos de científicos por aventurarse, investigar y categorizar elementos de la realidad natural. A fines del siglo XIX se organizaron campañas colonizadoras (que terminaron repartiéndose África) y se promovieron, desde Europa, expediciones científicas a distintos lugares de Latinoamérica.

El romanticismo en el Perú arraigó de diferentes maneras. Tuvieron predilección por la versificación apasionada e intensa. La poesía se tiñó de sentimentalismo. La trama narrativa giró en torno a amores imposibles, a la fatalidad del destino que impide la consumación del amor sublime. Atala de Chateaubriand es un ejemplo claro de la imposibilidad de consumar la plenitud y magia del amor. Algo se interpone, como ocurre también en María, de Jorge Isaacs. En el caso de Luis Benjamín Cisneros, un relato breve como Amor de niño revela de qué manera el tema se había convertido en un tópico recurrente. En ese relato, el niño Ricardo, de 8 años de edad, está atraído (enamorado) de Virginia, una joven de 
18 años. Se trata de un amor inocente y sincero. Los padres de Ricardo tratarán de alejarlo de Virginia. La joven viaja y se casa con su pretendiente. Cuando Ricardo se entera del distanciamiento definitivo de Virginia, estalla en llanto. Lo conmovedor es que:

Ese llanto se prolongó por algunos días por accesos frecuentes. Ricardo se volvió pensativo. Su carácter tomó cierta tendencia a la tristeza, sus movimientos de expansión y de júbilo desaparecieron, y hasta en sus sonrisas se veía una expresión de amargura. Pocos días después, los síntomas de una enfermedad mortal vinieron a aterrar el corazón de los padres. Ricardo comenzó a caer al suelo repentinamente y sin sentido (1939: 320).

Otra de las características del romanticismo fue el gusto por narrar hechos y acontecimientos lejanos (o remotos) o de tiempos pasados. Alejandro Dumas y Gustave Flaubert destacan entre los narradores de temas históricos. En nuestro medio, Ricardo Palma asume esa tendencia aunque él modificará las convenciones establecidas para imponer un estilo, un modo de narrar al que llamaría tradiciones peruanas.

Gran parte de sus tradiciones se ubican en tiempos del virreinato o los inicios de la República. Sin embargo, a Palma le interesaba también que sus relatos sean verosímiles, acaso por eso no dejaba de recurrir a los parrafillos históricos. Palma agrega, como algo propio, ese humor que había aprendido de los costumbristas, pero los supera al tomar de la cultura oral lo que era parte de la conciencia colectiva, especialmente la idiosincrasia del criollo. Palma supo darse cuenta de que algunos relatos estaban en el imaginario popular y había que escribir sobre ello.

En el Perú, los intelectuales y artistas del romanticismo vivieron de espaldas a la realidad. La lucha por el poder, la aventura política y las revueltas eran motivo suficiente para 
ser recreados. Los narradores prefirieron ignorar ese presente. Ni siquiera se interesaron por la pequeña historia regional y los relatos populares. No hubo interés por asumir la literatura, la creación en sí, de modo innovador. Cornejo Polar señala que: "[...] nuestros poetas románticos repetían temas y formas propios de maestros franceses, españoles y - con menor medida - alemanes. Desolación, soledad, incomprensión, desengaño y muerte aparecen constantemente en su poesía, como también los símbolos típicos del mar, el crepúsculo, las aves o las ruinas" (1980: 33).

\section{La novela realista, su propósito y proyección}

La guerra con Chile (1879-1883) es un punto de quiebre en la historia nacional. La guerra desestructura, genera el caos y deja en el país el sentimiento del deshonor. Pese al gesto heroico de Grau y Bolognesi, el país quedó devastado. Como en ningún otro caso, la guerra exigía una actitud de reflexión, de crítica nacional. $\mathrm{Y}$ es entonces cuando surge la figura de Manuel González Prada (de ancestros aristócratas, pero consciente de la necesidad de reformar el país), quien con extraordinaria lucidez critica la situación política, los gobiernos, el orden social. Plantea, de alguna manera, la necesidad de refundar el país que, hasta entonces, no era representativo de lo que era el Estado, la nación. Su histórica frase fue reveladora: "No forman el verdadero Perú esas agrupaciones de criollos y extranjeros que habitan la franja de tierras situada entre el Pacífico y los Andes; la Nación está formada por los dos o tres millones de indios diseminados en la banda oriental de la cordillera" (2009: 55).

González Prada reclama por la situación del indígena, critica al clero y la inmoralidad. Aspira a un verdadero ejercicio de la democracia que la aristocracia no ha permitido. Como se 
sabe, su prédica influirá decisivamente entre los intelectuales que son conscientes de la postración y el deshonor del país.

La figura de González Prada es relevante y trascendente, pero sería injusto desconocer que luego de la independencia se manifestaron, entre los indígenas, reacciones de descontento por las injusticias. Prueba de ello es la rebelión de Huancané, en 1867. Poco tiempo después apareció en la modalidad de folletín una novela corta titulada Los desheredados, de José L. Recabarren [1870], dato que consigna Maud Yvinec (2014). La novela representa a Santiago como justiciero. Un indio anciano le dijo: "[...] los blancos han entrado en tu casa, es preciso abandonarla; en un día te han quitado a tu padre y a tus dos hijos luego te quitarán tu mujer, tu último hijo, tus ganados, y cuando nada tengan que quitarte se apoderarán de ti mismo" (Recabarren [1870]: 136). Y Santiago, que no se amilana ante la adversidad, responde: "[...] te juro que no comeré ají mientras vivan esos dos bandidos, y si no puedo alcanzarlos, echaré medio a la lámpara y se consumirán (...) más de sesenta indígenas de ambos sexos rodearon al cadáver y empezaron a exhalar aullidos que levantaban un eco de muerte en los cerros vecinos" (Recabarren [1870]: 137). Nótese que en la obra de Recabarren se aprecia un primer esfuerzo de la clase criolla por acercarse a la realidad de los otros, un acercamiento por entender la cólera, la furia de los indígenas que ya daban señales de amenaza, de violencia colectiva contra la injusticia.

132 Entre las intelectuales que acogen la prédica de González Prada están Mercedes Cabello y Clorinda Matto de Turner. Mercedes Cabello opta por una actitud crítica acerca del acontecer nacional. Ella denuncia la miseria moral de los gobernantes y de los sectores medios que merodean el poder. En sus novelas pretende metaforizar la realidad nacional, aunque se deja llevar por situaciones o casos particulares que sucedían en ese momento. La inmediatez la atrapa. Ella 
publicó: Sacrificio y recompensa (1886), Los amores de Hortensia (1887), Las consecuencias (1888), Blanca Sol (1888) y unos años después El conspirador (1892).

En una reflexión importante sobre la novela moderna, Mercedes Cabello consideraba que: "[...] el romanticismo ha dañado los corazones por exceso de ficción e idealismo" (1948: 21). Reconocía que la publicación Nuestra señora de París, de Víctor Hugo terminó por convencer a la crítica y a los lectores que se aproximaban tiempos de cambio. Cabello consideraba que la obra mencionada: “[...] fue la nota más alta de la escuela romántica que aportaba como complemento de lo bello -que es parte no tanto del arte cuanto del hombrelo grotesco y lo feo" (1948: 21). Tales amores imposibles y los personajes grotescos, no hubieran sido posibles con el neoclasicismo. Pero mientras Víctor Hugo articula en su novela una trama sentimental de amores imposibles con un final dramático pero verosímil, los imitadores no tuvieron la habilidad y la creatividad para seguir explorando en torno a la compleja naturaleza humana. La literatura latinoamericana en pleno proceso de formación y definición, no pudo evitar la imitación. Cabello señala que:

A la exaltación producida en Francia por Atala, de Chateaubriand y el Rafael, de Lamartine, corresponde María, de Jorge Isaacs y Julia y Edgardo de Cisneros, y otras tantas del mismo idílico sabor. A la época romántica de Jorge Sand y Octavio Feuillet corresponden las bellísimas novelas de Juana Manuela Gorriti (...) A las novelas históricas de Dumas y Fernández y González, responden la Amalia, de Mármol, en la Argentina, la de Riva Palacios, en México y las de la señora Acosta en Colombia” (1948: 23).

Mercedes Cabello enfila su crítica contra el naturalismo de Zolá porque, según ella, carece de ideales, atrofia el sentimiento y suprime el ser moral del hombre (1948: 21). Cuestionó al naturalismo porque, desde su perspectiva, se des- 
cribía excesivamente el lado instintivo de los humanos en desmedro de sus valores y principios éticos. Decía: "[...] el hombre que ama, cree y espera; el que siente, piensa y lucha contra sus propias pasiones ¿dónde está en la novela de Zolá?" (1948: 28).

Para Cabello, los planteamientos y enfoques del naturalismo de Zolá no eran aplicables a América Latina porque, según ella, nuestra juventud es distinta. Se observa que en Mercedes Cabello prevalece una actitud proteccionista. Es verdad que la sociedad y las costumbres del Perú mostraban una nación conservadora. El catolicismo, a su vez, rechazaba los casos de degradación moral que los novelistas reflejaban en su obra. Lo que no parece haber entendido Cabello es que la novela del siglo XIX representa los efectos de la crisis económica derivados del industrialismo. Crisis que se manifestaba en una quiebra de valores y posibles casos de degradación moral. Cabello condena la presentación de una atmósfera sórdida o los límites a los que pueden llegar las personas por efecto de la ambición o el rencor. En las novelas realistas más representativas (La taberna y Naná de Zolá; Eugenia Grandet y Papá Goriot de Balzac) la crisis económico-social deriva en una degradación familiar.

A Cabello le preocupa que la novela moderna europea no presente una alternativa esperanzadora. Cabello adopta una posición ecléctica y señala que la novela debe presentar los problemas de una realidad social en crisis, pero a la vez debe

134 mostrar la importancia de la familia para contribuir a la formación de individuos íntegros. Para ella, el escritor no debería revelar el mundo del instinto, ni las deformaciones morales. No obstante esa prédica y la condena al escenario en el que las mujeres, agobiadas por sus problemas, terminan en la prostitución (como el caso de Nanâ), Mercedes Cabello, en su mejor novela (Blanca Sol), presenta los aconteceres de una familia que luego de lujos y ostentación termina en la ruina. En el momento más álgido, próximo a la debacle, la emplea- 
da que deseaba abandonar la casa, fue convencida para que se quede. En realidad, el relato muestra la dimensión de la crisis y la verdadera razón por la que se quería ir la empleada: "No era por falta de pago de sus salarios por lo que ella quería irse, no, es que el pulpero de la esquina, la amenazaba con llevarla a la Intendencia de Policía, caso que ella no llegara a pagarle cincuenta soles que le debía y esta enorme deuda, provenía de las mil necesidades se originaban en la casa [...]" (2004: 210).

En el desesperado afán por revertir su ruina, Blanca Sol decidió organizar un festín. Invitaría a sus amigos, pero no para pedirles ayuda sino diciéndoles: "Ven, acompáñame a perderme" (2004: 210). La narradora advierte que recibió a sus invitados en una bata de casa con lo que insinuaba lo que podría esperarse de ella. Luego, se hacía la siguiente reflexión: "¿Qué pierdo esta noche? Y se contestaba a sí misma. ¡Nada, puesto que el honor y mi reputación la he perdido ya! Pero si no pierdo nada, puedo ganar mucho, mucho (...) ¡Mañana habrá dinero para pagar mis deudas!” (2004: 211).

Los temas que inquietaron a la escritora reflejan lo que acontecía en la sociedad del siglo XIX. De modo que, como novelista, cumplió con recrear novelas que revelan los efectos de una crisis social, las ambiciones de poder y la crisis moral. Al comentar la obra de Mercedes Cabello, Arambel-Guiñazú comenta: "Como en las novelas de Balzac, el autor admirado, los personajes de Cabello pertenecen a la burguesía, la clase social a la que hace responsable de los males peruanos, instaladas en el poder y, gracias a las riquezas que han adquirido en las industrias guaneras y salitrera, llevan un tren de vida licencioso, ocupadas en modas y fastos con los cuales estas burguesías buscan deslumbrarse a sí mismas" (2001: 191).

Otra conclusión importante es que, al parecer, no tenía muy clara la idea de lo que significa la novela, la construcción de una trama narrativa organizada en función de puntos de 
interés dramático. La recreación novelada, en muchos casos, es la simple narración de un episodio sin el manejo del suspenso. Como novelista, Mercedes Cabello se deja ganar por la importancia del tema que está narrando. Le gana el afán de "fotografiar" la realidad social. No se esmera en la prosa, la articulación de secuencias, ni el ritmo narrativo. Pareciera que más le interesa que el lector pueda establecer relaciones entre lo novelado y el referente real.

En el arte de narrar, Clorinda Matto de Turner tuvo mejores logros. Matto prueba que tiene un mejor manejo de la trama narrativa. Además, devela la injusticia que se comete con los indígenas, un tema casi ausente en la narrativa de las primeras décadas de la república. Matto configura un escenario en una aldea rural en el que los notables, las autoridades y el clero hacen un frente común contra los indígenas. En determinado momento, cuando Marcela iba a acompañar a una comitiva que iba a quejarse ante la gobernación, Lucía la detiene para preguntarle cuánto le debe al cura. Marcela respondió:

- Por el entierro de mi suegra, cuarenta pesos, niñay.

- ¿Y por esto te embargó la cosecha de papas?

-No, niñay, por los réditos.

- ¿Por los réditos? ¿Así es que ustedes habrían quedado eternamente deudores? -preguntó con gesto significativo la señora de Marín” (1968: 60).

La novela consigue proponer un final sorprendente porque cuando Manuel y Margarita reafirman el sentimiento amoroso que los une, se enterarán de que Manuel es hijo del obispo don Manuel Miranda y Claro. Y Lucía revelará, por su lado, que Marcela le confesó que Margarita no era hija del indio Yupanqui, sino del obispo Claro. En consecuencia, eran her- 
manos y el amor era imposible. Si se consumara, sería una relación incestuosa. Un final impactante, doloroso, pero con ciertos rezagos románticos al tratarse de un amor imposible.

Pese a la descarnada denuncia, hay que anotar que el indígena no tiene un rol protagónico en la defensa de sus derechos. En el desarrollo de la trama, la injusticia de las autoridades o el abuso del clero no lo resuelven los indígenas, sino los esposos Marín que son criollos, forasteros en la zona. Solución momentánea. El problema del indígena era un problema de la propiedad de la tierra y ello no se revelaría sino en la novela indigenista del siglo XX a través de Alegría y Arguedas.

En conclusión, de acuerdo con lo argumentado, sostenemos que es erróneo considerar que la literatura siguió siendo colonial hasta la aparición de González Prada o el movimiento colónida. La literatura peruana dio muestras de cosmopolitismo desde las primeras manifestaciones del romanticismo. De hecho, los movimientos románticos y realistas reconocen la influencia de la literatura francesa. En segundo lugar, a mediados del siglo XIX, cuando la nación tuvo cierta bonanza, se crearon las condiciones para que el Estado respalde el quehacer cultural y se convierta en mecenas de poetas y escritores.

Es importante precisar que, durante el proceso de configuración de la literatura nacional, el costumbrismo de los primeros años de la república asumió un nosotros ante la imagen del otro, identificado por el colonizador español. Años después, a mediados del siglo XIX, los intelectuales románticos no se interesaron por un acercamiento al otro, sujeto de la acción social representado por la población indígena, por los marginados que no tenían acceso a las decisiones del gobierno central. La guerra con Chile demandó un análisis crítico del país. La figura de González Prada es decisiva por su percepción crítica del país, visión que coincide con la aparición del 
realismo literario en el Perú. Las obras de este periodo, tanto las de Mercedes Cabello, Clorinda Matto y Recabarren, buscan un acercamiento a los otros. Una actitud de los escritores que será una constante en toda la primera parte del siglo XX.

Recibido: 4 de junio del 2015

Aceptado: 01 de julio del 2015

\section{Bibliografía}

ARAMBEL-GUIÑANZÚ, Cristina y Claire Emilie MARTÍN 2001 Las mujeres toman la palabra; la escritura femenina en el siglo XIX. Madrid: Ediciones Iberoamericana, 2 volúmenes.

CABELLO, Mercedes

2004 Blanca Sol. Madrid: Ediciones Iberoamericana.

$1948 \quad$ La novela realista: ensayos filosóficos. Lima: Ediciones Hora del Hombre.

CISNEROS, Luis Benjamín

1939 Obras completas. Lima: Gobierno del Perú.

CORNEJO POLAR, Antonio

138

1980 Literatura del Perú republicano. Lima: Ediciones Mejía Baca, tomo VIII.

GONZÁLEZ PRADA, Manuel

2009 Ensayos. Lima: Editorial Universitaria de la Universidad Ricardo Palma.

LUKÁCS, George

1968 Sociología de la literatura. Barcelona: Ediciones Península. 
MARIÁTEGUI, José Carlos

19527 ensayos de interpretación de la realidad peruana. Lima: Editora Amauta.

MATTO DE TURNER, Clorinda

1968 Aves sin nido. Buenos aires: Ediciones Solar.

OVIEDO, José Miguel

1965 Genio y figura de Ricardo Palma. Buenos Aires: Editorial Universitaria.

2005 Historia de la literatura hispanoamericana. Madrid: Alianza Editorial.

PALMA, Ricardo

1968 Tradiciones peruanas completas. Madrid: Ediciones Aguilar.

PORRAS BARRENECHEA, Raúl

1997 Perspectiva y panorama de Lima. Lima: Ediciones Entre Nous.

RAMOS, Julio

1989

Desencuentros de la modernidad en América Latina. Literatura y política en el siglo XIX. México, D.F.: Fondo de Cultura Económica.

RECABARREN, José L.

2014 [1870] Los desheredados. Lima, periódico "El Nacional". En: HUÁRAG ÁLVAREZ, Eduardo (compilador). Violencia social y política en la narrativa peruana. Lima: Pontificia Universidad Católica del Perú, Instituto Riva Agüero. <http://repositorio.pucp.edu.pe/ index/bitstream/handle/123456789/46625/ViolenciaSocial3.pdf? sequence $=1>$

RIVA AGÜERO, José de la

1962 Estudios de literatura peruana. Carácter de la literatura del Perú independiente. Lima: Pontificia Universidad Católica del Perú. 
SÁNCHEZ TRIGUEROS, Antonio

$2000 \quad$ Sociología de la literatura. Madrid: Ediciones Síntesis.

TAUZIN, Isabelle

1999 Las tradiciones peruanas de Ricardo Palma. Lima: Editorial Universitaria de la URP.

THIBAUDET, Albert

1957 Historia de la literatura francesa. Buenos Aires: Editorial Losada.

VELÁZQUEZ, Marcel

2005 "Género, novelas de folletín e imágenes de la lectura en la ilustración y el romanticismo peruanos". Lima, Revista Mora Ediciones de la UNMSM.

YVINEC, Maud

2014 La expresión de una violencia sorda o el preludio del indigenismo peruano. Apuntes sobre una novela de folletín escrita a raíz de la rebelión de Huancané de 1867. En HUÁRAG ÁLVAREZ, Eduardo (compilador). Violencia social y política en la narrativa peruana. Lima: Pontificia Universidad Católica del Perú, Instituto Riva Agüero. <http://repositorio.pucp.edu. pe/index/bitstream/handle/123456789/46625/ ViolenciaSocial3.pdf?sequence $=1>$ 